\title{
Gestão organizacional e perspectivas institucionais: análise da postura estratégica da Cooperativa Agropecuária Vista Alegre Ltda.
}

\author{
Organizational management and institutional perspectives: analysis of the strategic posture of \\ the Cooperativa Agropecuária Vista Alegre Ltda
}

\begin{abstract}
Resumo
Esta investigação teve por objetivo identificar e analisar a estratégia competitiva adotada por uma cooperativa de assentados da reforma agrária, voltados para a produção láctea. Utilizou-se o método de Estudo de Caso e aplicou-se as análises Matriz FOFA (Forças, Fraquezas, Oportunidades e Ameaças) e Estratégias Genéricas de Porter como embasamento teórico. Para tanto, se resgatou o processo de constituição da cooperativa, verificando as características do ambiente institucional e organizacional da mesma, assim como, a análise da forma de participação dos sócios. Os resultados mostram a predominância de pontos fortes no ambiente interno e ameaças no ambiente externo, o que coloca a instituição numa postura de manutenção. Focada na produção e industrialização láctea de base agroecológica, observa-se que a estratégica competitiva de diferenciação adotada é adequada aos propósitos da organização, que não teria escala para competir em custo. Com este estudo observa-se que é complexa a gestão de uma organização que tem por princípio a cooperação, mas atua num ambiente altamente competitivo.
\end{abstract}

Palavras-Chave: Ambiente Interno; Ambiente Externo; Assentamento.

\begin{abstract}
This article aims to ascertain the competitive strategy adopted by a cooperative of farmer from agrarian reform, focused on milk production, comprehending their acting environment, highlighting organizational and administrative aspects, through a case study and the application of the SWOT. Therefore, one proposes the rescue of the cooperative's constitution process, verifying institutional environment and organizational characteristics, such as an analysis of the partners' participation form. The results point to the predominance of strong points in the internal environment and threats in the external environment, which puts the institution, in a maintenance posture. Focused on the production and industrialization of milk products from agro ecological basis, one can observe that the adopted competitive strategy of differentiation is adequate to the organization's purposes. This study is observed that complex is the management of an organization whose principle cooperation, but operates in a highly competitive environment. Despite some difficulties, it appears that it is possible to keep alive the 'flame' of cooperative work by solidarity, participation and collective work.
\end{abstract}

Keywords: Internal Environment; External Environment; settlement land reform.

Recebido: 25/10/2016 Aceito: 09/01/2017

Janaína Balk Brandão ${ }^{1}$, Raquel Breitenbach ${ }^{2}$ e Alzenei Valentin Dalpra ${ }^{3}$

1Universidade Federal de Santa Maria, Mestre e Doutora em Extensão Rural - janainabalkbrandao@ hotmail.com - Rua Silva Jardim, 1496, 204, Santa Maria - RS, CEP 97010-490

2 Instituto Federal de Educação, Ciência e Tecnologia do Rio Grande do Sul, Mestre e Doutora em Extensão Rural -

raquel.breitenbach@sertao.ifrs.edu.br

${ }^{3}$ Universidade Federal de Santa Maria, Bacharel em Administração - alzeneidalpra@ hotmail.com 


\section{Introdução}

$\mathrm{F}$ ace ao imperativo da alta competição dos mercados modernos, entendidos também como modificação dos padrões de intercâmbio comercial e de geração e difusão de conhecimento e tecnologia, muitos desafios se apresentam para o cooperativismo. Dentre esses, ressalta-se: a profissionalização, o relacionamento interno cooperativa/cooperado, a falta de orientação para o mercado e a descapitalização (VALADARES, 2014). Em muitas organizações, incluindo as cooperativas, existem dificuldades de gestão, resultando na não maximização dos pontos fortes e oportunidades, bem como não desenvolvimento de estratégias com vistas a corrigir os pontos fracos e minimizar as ameaças (SEBRAE, 2015).

De modo geral, a gestão de organizações cooperativas, acontece de forma linear, horizontal, em que se tem uma equipe de coordenação, direção e equipe de execução. Porém, a responsabilidade legal segue sendo da direção, a qual faz a gestão das organizações. O poder lhes é dado por instrumentos legais como atas de eleição, procurações, entre outros. Assim, embora representem interesses comuns dos associados para que a cooperativa obtenha sucesso no longo prazo, é necessário que utilizem estratégias apropriadas para o seu foco de atuação ou para a execução de um projeto em particular (MONTANO, 2012).

Alerta-se ainda, que as cooperativas atuam nos mesmos mercados que as demais empresas, demandando, para sua sustentabilidade, da obtenção de resultados econômicos positivos para a repartição aos cooperados. Considerando esses aspectos, fica evidente que obter equilíbrio gerencial entre os diferentes níveis de interesse dos associados é um desafio para as cooperativas (MACHADO, 2013).

Dentro desta perspectiva, o objetivo geral desta pesquisa é analisar as estratégias de gestão de uma cooperativa dedicada à produção e processamento de produtos lácteos. Buscou-se compreender sua postura estratégica a partir das metodologias de análise da Matriz FOFA (Fortalezas, Fraquezas, Oportunidades e Ameaças) e Estratégias Genéricas de Porter. Para tanto, verificou-se como a cooperativa se posiciona frente a um mercado altamente competitivo e tendo que responder de forma linear e cooperada diante de seus 'inúmeros donos'. Somado a isso, faz-se uma averiguação dos aspectos que levaram a constituição da cooperativa, verificando as características do ambiente institucional que compunha o cenário da época, analisando como se dá a tomada de decisões e participação das pessoas que a compõe.

Para tanto, apresenta-se a seguir a metodologia de pesquisa adotada. Na sequência, os resultados obtidos são analisados à luz da matriz FOFA. Ao final, fazem-se as considerações finais.

\section{Referencial Teórico}

\subsection{Matriz FOFA}

O presente artigo está alicerçado em duas principais metodologias de análise: a Matriz FOFA e as Estratégias Genéricas de Porter. Ambas as teorias são comumente utilizadas juntas, já que a primeira tem um cunho de análise de ambiente interno e externo da organização, mapeando a situação atual da mesma, enquanto que a segunda analisa as estratégias adotadas. Portanto, se utilizadas juntas, tais metodologias dão conta de conhecer a empresa, suas estratégias, bem como avaliar se tais estratégias estão de acordo com o ambiente enfrentado pela empresa.

A Análise FOFA se consolidou como uma ferramenta eficaz no diagnóstico estratégico, uma vez que sua estrutura demonstra com facilidade os valores destacados na análise, agilizando a tomada de decisões. Formada com quatro palavras chaves: forças, fraquezas, oportunidades e ameaças, objetiva destacar os pontos adequados e adversos de questões externas e internas da organização analisada (HELMS, 2010).

Segundo Henriques (2004) a análise das Fortalezas, Fraquezas, Oportunidades e Ameaças (FOFA) conhecida na língua inglesa por SWOT (Strenghness, Weakness, Opportunities, Threats) torna-se importante instrumento para a viabilização de uma gestão estratégica. Segundo Azevedo e Costa (2001) esta matriz começou a ser desenvolvida nos anos 60, nas escolas americanas de administração. $\mathrm{O}$ objetivo básico é definir estratégias para manter pontos fortes, reduzir a intensidade de pontos fracos, aproveitando as oportunidades e proteger-se das ameaças.

Assim, a partir da análise FOFA a organização pode adotar quatro posturas estratégicas que são: sobrevivência, crescimento, manutenção e desenvolvimento (OLIVEIRA, 1999), conforme descritas a seguir: 
A) Postura de Sobrevivência- Somente quando não houver alternativa deverá ser adotada este tipo de postura pela organização. Identifica-se pela predominância de pontos fracos e ameaças e quando o ambiente e a organização estão em situação inadequada. Neste caso, a empresa deverá ter estratégias de redução de custos, desinvestimento e liquidação de negócio.

B) Postura de Manutenção- Predominância de ameaças do ambiente externo, mas internamente a empresa possui uma série de pontos fortes acumulados ao longo do tempo, que possibilitam além de continuar sobrevivendo, manter a posição conquistada até o momento. Deverá usufruir ao máximo seus pontos fortes com vistas a minimizar os pontos fracos e maximizar os pontos fracos da concorrência. Esta postura poderá desencadear em três situações: estratégia de estabilidade, estratégia de nicho, e estratégia de estabilização.

C) Postura de Crescimento- Caracteriza-se pela predominância de pontos fracos, onde o ambiente proporciona situações favoráveis que pode transformar-se em oportunidades, é indicado nesta fase, lançar novos produtos, e aumentar o volume de vendas. As estratégias inerentes a esta postura são: estratégia de inovação, estratégia de internacionalização, estratégia de joint venture, estratégia de expansão.

D) Postura de Desenvolvimento- Pontos fortes e oportunidade predominam neste caso, é o momento de desenvolver a organização, através de novos mercados e clientes ou procurar novas tecnologias. Construir novos negócios no mercado. Este desenvolvimento poderá assumir as conotações: Desenvolvimento de mercado, desenvolvimento de produtos ou serviços, desenvolvimento financeiro, desenvolvimento de capacidades e desenvolvimento de estabilidade.

\subsection{Estratégias Genéricas}

Estratégia diz respeito a ser capaz de posicionar-se corretamente frente às situações, principalmente quando se está diante de incertezas e turbulências do ambiente. Diante das reformulações provocadas pela economia mundial, das redefinições do papel do Estado e das desigualdades sociais crescentes e mais profundas em todo o mundo. As organizações do terceiro setor se veem confrontadas com a necessidade de redefinir rumos e buscar alternativas de atuação para poderem sobreviver. Se, por um lado, conquistaram espaço na sociedade, por outro, se veem na iminência de perder terreno. Assim, os planos plurianuais, por exemplo, se mostram insuficientes para que as organizações se posicionem corretamente perante o ambiente (REIS, 2013).

Porter (1986) constituiu estratégias para diferenciar as principais áreas de negócios, objetivando fundar vantagens e maior lucratividade nos negócios. Segundo esse autor, há pelo menos dois tipos básicos de vantagens competitivas que uma empresa pode estabelecer: custos baixos ou diferenciação. Isso, combinado com o "escopo" de operação, gera três distintas estratégias no sentido de atingir desempenho acima da média: liderança de custos, diferenciação e foco (PORTER, 1986).

Mesmo com este cenário moderno as contribuições de Porter (1986) ainda são pertinentes quando conceitua o que é uma estratégia competitiva. Esta se refere a como uma 'empresa' decide competir em um mercado em resposta às estratégias e posições de seus competidores, de modo a ganhar uma vantagem competitiva sustentável. Conforme Porter (1986) as estratégias competitivas genéricas estão baseadas em duas definições básicas: (1) Escopo de atuação (largo ou estreito) e (2) Tipo de vantagem competitiva (baixo custo ou diferenciação). Definido o posicionamento estratégico da empresa, através da escolha de uma estratégia competitiva genérica a ser perseguida, o passo seguinte seria a definição das vantagens competitivas sustentáveis a serem desenvolvidas ou aproveitadas, a partir das competências e recursos disponíveis na empresa.

\section{Metodologia da pesquisa}

Esta pesquisa foi realizada ao longo do ano de 2015 e se enquadra como Estudo de Caso, pois analisa profundamente um caso específico, nesse caso uma organização (YIN, 2001). Esta organização refere-se a Cooperativa de Produção Agropecuária Vista Alegre de Piratini Ltda. (COOPAVA).

Considera-se esta também, uma pesquisa exploratória, pois objetiva proporcionar maior familiaridade com o problema, com vistas a torná-lo mais explícito ou construir hipóteses (DIEHL E TATIN, 2004). Para obtenção dos dados necessários para a análise do objeto de estudo os instrumentos utilizados foram: observação; aplicação de questionários aos associados; acesso e análise da 
documentação da organização; entrevistas de profundidade (presidente); e pesquisa através de grupo focal (diretores). A realização da entrevista com o presidente da instituição se deu através do roteiro pré-estabelecido, buscando obter informações sobre a situação atual da instituição, interação com os demais setores (governo e empresas privadas). Já a utilização do questionário com vinte associados da instituição permitiu a obtenção de dados quantitativos ao mesmo tempo em que proporcionou a captura das impressões particulares dos entrevistados.

A obtenção da visão dos associados se deu através da ferramenta Grupo Focal. Tal ferramenta possibilita tanto a coleta de dados objetivos - que, entretanto, poderiam ser obtidos por outros meios - quanto de dados subjetivos, os mais importantes (TURATO, 2003:313). As informações obtidas através do grupo contribuíram na compreensão das divergências de opiniões entre estes atores. Para tanto, adotou-se um roteiro semi-estruturado estabelecido a partir das necessidades verificadas por ocasião da análise dos questionários.

Para complementar os dados primários levantados, também se utilizou a observação direta e participante. Neste método o pesquisador passa a fazer parte da rotina da empresa no período de pesquisa o que lhe permite uma compreensão de sua atuação. Isto contribui no processo de análise, pois joga sob o objeto uma visão externa a adotada na empresa (DIEHL E TATIN, 2004; HAGUETTE, 2005). O levantamento de dados a partir do acesso a documentação da organização se deu através da análise de atas e contratos, atos constitutivos, demonstrativos de resultados, manuais, regimentos e instrumentos administrativos. Primeiramente foram buscados os indicadores quanto ao nível interno à organização, elencando pontos fortes e pontos fracos. $\mathrm{Na}$ sequência foram apontados indicadores em nível externo à organização, elencando as oportunidades e ameaças.

Como método para avaliação dos pontos fortes e fracos, oportunidades e ameaças da organização, utilizou-se o modelo SWOT; para definir e avaliar as estratégias utilizadas pela cooperativa, a metodologia utilizada foi das Estratégias Genéricas de Porter.

O método de análise utilizado teve como propósito verificar a frequência dos fenômenos procurando identificar relações entre eles, partindo de uma interpretação dos dados com modelos conceituais definidos a priori. O conjunto desta técnica é denominado como análise de conteúdo, conforme Minayo (1994). Foram atribuídos valores aos fatores estratégicos considerados, através de uma escala, 1-59 (no qual 1 significa pouca incidência $\mathrm{e}$ significância, 5 nível intermediários de incidência e significância e 9 forte incidência e significância). O objetivo da escala é a quantificação das ocorrências, de acordo com a repetição (SOUZA, 2005). A predominância entre os fatores estratégicos foi obtida através dos somatórios e comparações entre valores maiores e menores para cada fator, da seguinte forma (SOUZA, 2005):

\section{Se, $\sum$ Pontos Fracos $>\sum$ Pontos Fortes}

Ameaças $>$ oportunidade $=$ Postura de Sobrevivência

Ameaças $<$ oportunidades $=$ Postura de Crescimento

Se, $\sum$ Pontos Fracos $<\sum$ Pontos Fortes

Ameaças $>$ oportunidades $=$ Postura de Manutenção

Ameaças $<$ oportunidades $=$ Postura $\mathrm{de}$ Desenvolvimento

Os dados quantitativos foram tabulados e analisados através de técnicas estatísticas simples como percentuais e coeficientes, séries históricas, com ênfase nas tendências de evolução da organização.

As informações qualitativas foram interpretadas com base nas teorias utilizadas. Para tanto, foram montados grupos de respostas por blocos, obtidos a partir dos instrumentos de pesquisa. Estas questões foram somadas com as questões quantitativas a fim de melhorar a visão sobre a problemática vivida pela empresa. Ou seja, os dados dos questionários aplicados foram analisados e sistematizados por grupos que por sua vez estão divididos por questões, da mesma forma foi feito com as entrevistas.

Para a análise do ambiente interno da organização utilizou-se os questionários aplicados aos associados da organização e, ainda, a própria entrevista com o presidente e análise documental, a qual objetivou obter informações do processo interno aplicando a matriz fofa. Após a análise dos dados levantados na pesquisa foi formulado o escopo da estratégia num sentido propositivo para a organização pesquisada. 


\subsection{Caso analisado}

A Cooperativa de Produção Agropecuária Vista Alegre de Piratini Ltda. (COOPAVA) está sediada no município de Piratini/Rio Grande do Sul, é formada por famílias assentadas da reforma agrária deste município, contando com cinquenta e três associados que atuam na área de lácteos, com produção coletiva desde 2005. No contexto atual, a cooperativa está ampliando a indústria e inserindo novos produtos no mercado, o que demandará melhor posicionamento de mercado da mesma, incluindo o aprimoramento de suas competências básicas e compreensão de seus ambientes.

O presidente que ocupava o cargo quando da realização da pesquisa (que foi entrevistado) foi o primeiro presidente da organização e exerceu esta função por dois mandatos subsequentes, cada um por dois anos. Posteriormente, atuou como tesoureiro e vice-presidente. Novamente assumiu a presidência e atua nessa função nos últimos seis anos (2009 a 2015).

As eleições que ocorreram na organização sempre foram por consenso, e quando ocorrem altera-se pelo menos $1 / 3$ dos membros da direção e conselho fiscal.

Os associados da cooperativa são agricultores e/ou filhos de agricultores e possuem o seguinte nível de escolaridade: $80 \%$ possuem até o ensino fundamenta; $15 \%$ até o ensino médio; técnico contábil ou técnico agrícola, 5\%. Quanto à faixa etária, $30 \%$ dos associados tem até 50 anos; entre 50 a 55 anos, encontram-se $60 \%$ dos associados; e, com mais de 55 anos, encontram-se $10 \%$ dos associados.

As organizações do terceiro setor, ao qual pertence a cooperativa, não têm como objetivo final apenas o lucro, mas proporcionar a melhoria nas condições econômicas dos cooperados, da cooperativa e da comunidade onde está inserida. Isso é relevante porque através da referida Cooperativa, as pessoas têm conseguido produzir alimentos, conviver e habitar a terra que foi pretendida.

\section{Resultados e discussão}

\subsection{A COOPAVA}

A análise da documentação e as entrevistas permitiram a caracterização da COOPAVA. Esta foi fundada em 1995 pelas famílias do Assentamento Conquista da Liberdade, situado no $2^{\circ}$ distrito de
Piratini/RS. A mesma está localizada apenas três quilômetros da BR 293, o que proporciona fácil acesso tanto da matéria-prima quanto das rotas de distribuição de produtos ao mercado.

Atualmente, conta com um quadro social de cinquenta e três sócios (trinta e dois agricultores e vinte e uma agricultoras), com a produção em uma área de aproximadamente 400 hectares, explorados de forma coletiva. As famílias moram em uma agrovila e as moradias apresentam boas condições, contando com água oriunda de poço artesiano próprio e energia elétrica. Em cada residência, há tratamento de esgoto através de sistema ecológico e implantado de forma participativa pela Cooperativa de Prestação de Serviços Técnicos Ltda (COPTEC).

$\mathrm{O}$ desenvolvimento da COOPAVA precisa ser compreendido dentro de um contexto socioambiental específico. Ao chegarem à região as famílias assentadas se defrontaram com um agroecossistema desconhecido, pois eram provenientes do norte do RS, onde as condições de relevo e composição do solo são diferentes. $\mathrm{Na}$ região norte, há predominância do cultivo de grãos (soja, trigo, milho, etc.), já na região sul os campos favorecem a criação de gado de leite e de corte, onde o manejo das atividades agrícolas exigem outros conhecimentos agronômicos. Assim, a fundação da COOPAVA foi uma estratégia de fortalecimento para enfrentar estas adversidades, já que os solos rasos e com baixa fertilidade natural não se adequavam ao desenvolvimento de sistemas intensivos de produção (SMICH, 2002).

No período imediatamente posterior à instalação das famílias, a produção foi bastante diversificada. As principais atividades produtivas foram: a produção de grãos (soja, milho, feijão), fruticultura (pêssego), horta para o autoconsumo, produção de leite, ovinos, gado de corte e suínos. Em todas estas culturas se utilizava uma tecnologia convencional, ou seja, com uso de agrotóxicos e adubação química.

Nos anos de 1996 a 1998, com consecutivas estiagens, observa-se a baixa produtividade dos pastos e culturas agrícolas, que adicionados aos altos custos de insumos levaram a insustentabilidade econômica da produção. Os agricultores avaliaram neste momento que o modelo tecnológico convencional, além de ameaçar a reprodução social das famílias associadas, trazia risco de saúde às pessoas e levava a insustentabilidade ambiental em um contexto de um agro ecossistema sensível (solos 
rasos e de baixa fertilidade natural). Diante disso, definiram em assembleia que trabalhariam produção com base orgânica. Isso permitiu que a cooperativa produzisse, industrializasse e comercializasse um produto de boa qualidade.

Em 2005 a instalação de uma agroindústria de leite representou o amadurecimento produtivo, econômico e político do coletivo, considerando a necessidade de apropriação de novos conhecimentos e práticas. Esse processo desafiou os agricultores e o quadro de apoio técnico de assessoramento. Especialmente no período de instalação do projeto, já que esta proposta rompeu com paradigmas da formação acadêmica tradicional.

Diante da necessidade sentida para enfrentar as adversidades no período de consolidação da cooperativa, o aprendizado de novas tecnologias para diminuição dos custos de produção somou-se a necessidade de domínio da gestão administrativofinanceira.

Quando da realização da pesquisa, a cooperativa atuava na produção agropecuária (setor primário), na industrialização (setor secundário) e no comércio (setor terciário). A industrialização de leite é do Tipo C. As atividades da indústria se dão por setores organizados, os quais possuem seus coordenadores e as atividades são planejadas e socializadas com todos os setores da instituição. Acontece a cada ano uma Assembleia Geral Ordinária, em que um dos pontos de pauta é a análise das contas do ano pelo conselho fiscal, bem como o relatório de atividades apresentado pela direção; neste momento é decidido o destino do resultado financeiro, quando positivo. No caso de resultado negativo, a assembleia decide formas de sanar o débito de acordo com sua natureza e valor. Na prestação de contas anual são utilizados balancetes, balanços e relatórios contábeis.

A cooperativa acessa as políticas públicas de Programa de Aquisição de Alimentos (PAA) e Programa Nacional de Alimentação Escolar (PNAE). Estas políticas públicas são responsáveis por $30 \%$ das vendas da cooperativa.

Destaca-se que cerca da metade famílias associadas acessam o programa bolsa família e todas acessaram recursos de melhoramento de habitação através do Instituto Nacional de Colonização e Reforma Agrária (INCRA) e Caixa Econômica Federal.

Em análise à documentação da entidade, verificouse que a cooperativa buscou ampliação do processo de industrialização de leite e seus derivados, através de um projeto junto ao programa interministerial denominado Terra Forte. O mesmo está aprovado e aguardando liberação dos recursos para iniciar sua implementação. Como finalidade, o projeto prevê ampliação e modernização da capacidade de processamento e comercialização de leite e derivados, com capacidade de beneficiamento mensal de 126.000 litros.

O projeto levou a cooperativa a pensar e elaborar um plano de expansão de seu quadro de associados visando melhoria da produção de leite in natura, na qualidade e quantidade, pois a indústria irá demandar quantidade maior de matéria-prima. Assim, as tratativas indicam a necessidade de novos associados do próprio assentamento, sendo estes filhos de famílias já sócias; novos associados de famílias que residem no assentamento Piratini e assentamento Ferraria.

Para a implementação do projeto de ampliação do laticínio, a cooperativa conta com parceiros na gestão do estabelecimento, na assistência técnica, com cursos de capacitação, fornecimento de matéria-prima e no acesso aos mercados, conforme se observa no Quadro 1.

Com a ampliação da indústria serão agregados em torno de dez jovens do assentamento na realização das atividades relacionadas ao processamento agroindustrial e gestão da cooperativa. E, ainda, mais dez novos postos de trabalho nas atividades de gerenciamento de vendas e no setor de formação para associados.

A agroindústria também gerará mais empregos diretos e indiretos e aumento da arrecadação fiscal dos municípios envolvidos, o que resultará em melhorias para a população como um todo. Com a ampliação do empreendimento já existente junto ao assentamento e a modernização da nova estrutura da planta industrial, tem-se um melhor aproveitamento e otimização da mão de obra existente. Com isto, espera-se a ampliação da capacidade e melhoria da qualidade do ambiente de trabalho dos colaboradores/cooperados.

Em análise à documentação da instituição, percebe-se que as decisões na cooperativa se dão a partir de discussões nas instâncias onde as deliberações são tomadas e os coordenadores dos setores garantem sua efetivação. Especificamente na agroindústria, existem as figuras dos coordenadores dos setores que atuam a partir de discussões coletivas e democráticas, interagindo também com a direção. 
Acerca das estratégias da organização, Machado (2013) concluiu que a COOPAVA compete a partir dos seguintes direcionadores de competitividade: confiabilidade, rapidez, qualidade, custos e flexibilidade. $\mathrm{O}$ autor destaca ainda, que os diferenciais da COOPAVA se relacionam à produção em conjunto; ao fato da produção primária ficar junto da industrialização, facilitando a manipulação do leite até chegar à agroindústria; trabalha com duas fontes de matéria-prima, ou seja, o leite de unidades de produção dos assentados associados e o leite ordenhado na própria propriedade; além disso, como os cooperados produzem em conjunto, a dedicação dos mesmos aumenta, bem como tem menores encargos trabalhistas.

Por outro lado, Machado (2013) destaca também limitações da cooperativa. Segundo o autor, a contabilidade é realizada por um contador contratado e os associados enfrentam dificuldades para a compreensão dos resultados. Além disso, existe a preocupação dos associados em relação à permanência e continuidade dos jovens no assentamento, os quais têm optado por ir para o meio urbano estudar e não retornam para o assentamento.

\begin{tabular}{|c|c|c|}
\multicolumn{2}{|c|}{ Quadro 01 - Organizações parceiras da COOPAVA, tipo e finalidade de apoio. } \\
\hline $\begin{array}{c}\text { Parceiro } \\
\text { Companhia Nacional de Abastecimento } \\
\text { (Conab) }\end{array}$ & $\begin{array}{c}\text { Apoio } \\
\text { Comercial }\end{array}$ & Política agrícola \\
\hline $\begin{array}{c}\text { Cooperativa Central dos Assentamentos do Rio } \\
\text { Grande do Sul (Coceargs) }\end{array}$ & Gestão & Gestão cooperativa \\
\hline $\begin{array}{c}\text { Empresa de Assistência Técnica e Extensão } \\
\text { Rural (Emater) - Piratini }\end{array}$ & Técnico & $\begin{array}{c}\text { Assistência técnica rural e } \\
\text { elaboração de projetos }\end{array}$ \\
\hline $\begin{array}{c}\text { Universidade Federal de Pelotas (UFPel) } \\
\text { administrativa/cursos }\end{array}$ \\
\hline $\begin{array}{c}\text { Fundação Universidade Federal do Rio Grande } \\
\text { (Furg) }\end{array}$ & Técnico & Técnico \\
\hline $\begin{array}{c}\text { Prefeitura de Piratini } \\
\text { fabricação }\end{array}$ \\
\hline $\begin{array}{c}\text { Cooperativa de Comercialização e Prestação de } \\
\text { Serviços dos Assentados da Região Sul Ltda. } \\
\text { (Coopersul) }\end{array}$ & Parceria & $\begin{array}{c}\text { Fornecimento Matéria- } \\
\text { prima }\end{array}$ \\
\hline $\begin{array}{c}\text { Cooperativa Regional dos Agricultores } \\
\text { Assentados Ltda. (Cooperal) }\end{array}$ & Parceria & $\begin{array}{c}\text { Fornecimento Matéria- } \\
\text { prima }\end{array}$ \\
\hline Cooperativa Terra Livre & Parceria & Campo de recria \\
\hline $\begin{array}{c}\text { Programa Terra Forte/ Fundação de Amparo àra } \\
\text { Pesquisa e Extensão Universitária (FAPEU)/ } \\
\text { Universidade Federal de Santa Catarina } \\
\text { (UFSC) }\end{array}$ & Técnico & $\begin{array}{c}\text { Elaboração, } \\
\text { acompanhamento e } \\
\text { ampliação planta } \\
\text { agroindustrial }\end{array}$ \\
\hline $\begin{array}{c}\text { Comercialização de } \\
\text { produtos - mercado } \\
\text { convencional }\end{array}$ \\
\hline
\end{tabular}

\subsection{Análise do ambiente interno e ambiente externo}

A partir das informações obtidas na pesquisa empírica, se elaborou o cenário que compõe o ambiente interno, procurando identificar as competências essenciais da organização, conforme a esquematização apresentada no Quadro 2. 
Quadro 2: Definição dos principais pontos fortes e pontos fracos da COOPAVA.

\begin{tabular}{|c|c|}
\hline & $\begin{array}{c}\text { Bens coletivos de produção; Boa organização interna; Proporciona crescimento } \\
\text { coletivo/profissional e pessoal; Metodologia de trabalho coletivo; Bom modo de } \\
\text { gestão (transparência); Relação entre as pessoas; Envolvimento das pessoas na } \\
\text { tomada de decisões (setores de trabalho); Quadro de associados oriundos do } \\
\text { processo de reforma agrária; Compromisso dos trabalhadores com a cooperativa; } \\
\text { Autonomia para administrar o espaço de trabalho; Sintonia de objetivos; } \\
\text { Engajamento social; Trabalho com respeito ao meio ambiente (agroecologia); } \\
\text { Ambiente de trabalho com liberdade para criação; Empreendimento coletivo; } \\
\text { Construção coletiva de decisões; Experiência no negócio. }\end{array}$ \\
\hline & $\begin{array}{c}\text { Dificuldade financeira/dependência de recursos externos; Falta de uma estrutura } \\
\text { adequada para a realização das atividades; Pouca capacitação dos trabalhadores; } \\
\text { Falta de um planejamento a médio e longo prazo; Controle orçamentário e índices } \\
\text { de resultados ausentes; Pequeno número de funcionários (poucas pessoas face às } \\
\text { atividades demandadas). }\end{array}$ \\
&
\end{tabular}

Quando questionados sobre o planejamento, a maioria das respostas (97\%) apontam para uma boa participação das pessoas no processo de planejamento das atividades. Nota-se que mesmo informalmente, há um planejamento nos setores produtivos e as pessoas contribuem nesse planejamento e na execução das atividades. Nos demais setores, da mesma forma se visualiza um planejamento e relatórios que demonstram o registro das ocorrências, como por exemplo, a contabilidade. As equipes são divididas em grupos de trabalho nos setores. Nota-se que a forma de organização dá conta de que em cada posto de trabalho tenham equipes definidas, pois embora haja falta de um planejamento formal ele acontece junto aqueles que realizam as tarefas e atividades, fato que proporciona experiência de trabalho, aperfeiçoamento na gestão. Ou seja, no curto prazo as atividades são planejadas.

Um fato que merece destaque é a afinidade de objetivos, no qual $100 \%$ dos pesquisados dizem que seus objetivos estão em sintonia com os objetivos da instituição. Isso dá sustento à proposta e a organização.

É importante que os objetivos das pessoas estejam em sintonia com os objetivos da organização, este é o elo central, onde as demais questões são trabalhadas num segundo estágio com vistas à conquista de metas e objetivos de todos.

Reforça-se também o grau de comprometimento associados para com a proposta da cooperativa, destinando grande parte de seu tempo em função desta causa, conforme confirma o depoimento do Presidente da cooperativa: "Eu diria que de uma forma geral, todas as pessoas, os trabalhadores que estão na Cooperativa, eles têm prestado trabalhos voluntários muito além de suas oito horas de trabalho".

Acerca do modelo de gestão, a totalidade dos respondentes cita a forma adotada como a ideal, pois embora possua alguns limites ainda (especialmente sobre os controles e formas de avaliação das pessoas) é considerada eficiente e participativa. Esta forma se dá muito em função da ideologia e do social, o que é indispensável especialmente nesta forma de organização.

A divergência de opiniões que surgiu a partir da pesquisa individual diz respeito a concepção da rotina diária de execução do planejamento nos setores produtivos, acerca dos quais surgiram ideias e sugestões. A atividade de grupo focal permitiu a apresentação dessas ideias e a compreensão por todos de eventuais dúvidas, sendo que ao final da atividade com o grupo focal estas divergências foram sanadas.

Portanto, as divergências não estavam associadas à forma de gestão da cooperativa, neste quesito foi unânime entre os associados que a forma adotada é a melhor, bem como é democrática e transparente. Porém, algumas divergências surgiram no que se refere a forma de executar a atividade produtiva nas unidades de produção, especificamente relacionadas ao sistema de produção. Entretanto, cabe salientar que através de tais divergências foi possível o crescimento 
e o surgimento de idéias e novas formas de compor o planejamento.

Entretanto, uma questão observada é a dependência de recursos externos, oriundos especialmente do governo federal. A cooperativa vem mantendo algumas atividades com recursos de projetos específicos, como por exemplo, projetos para adubação, irrigação, veículos para transporte de produtos in natura e produtos industrializados, aquisição de patrulha agrícola. Destarte, a cooperativa possui debilidades no que tange a qualificação de profissionais para elaboração de projetos, acompanhamento e prestação de contas dos mesmos. Ações estas importantes para a manutenção da instituição, pensando em novos projetos e parcerias futuras. Conforme já colocava Andrade (2002), o terceiro setor vive o desafio da sustentabilidade organizacional, motivado pela dependência de fontes de recursos do governo, privados ou de organismos internacionais. Neste sentido, para oferecer benefícios sociais amplos, as cooperativas precisam primeiramente apresentar uma condição econômica sólida (FERREIRA, 2014).

No Quadro 3 observa-se a predominância de pontos fortes. Para cada item foi classificado e atribuído uma pontuação pela repetição de registros nos instrumentos de pesquisa, conforme segue:

Quadro 3 - Análise das variáveis internas (pontos fracos e pontos fortes) da COOPAVA.

\begin{tabular}{|c|c|c|c|c|c|c|c|}
\hline \multicolumn{8}{|c|}{ VARIÁVEIS INTERNAS } \\
\hline PONTOS FRACOS & $\mathbf{1}$ & 5 & 9 & PONTOS FORTES & $\mathbf{1}$ & 5 & 9 \\
\hline $\begin{array}{c}\text { 1- Escassez de recursos } \\
\text { financeiros limita as atividades }\end{array}$ & & & $\mathbf{x}$ & $\begin{array}{l}\text { 1- O fato de existir e resistir - } \\
\text { ideologia }\end{array}$ & & & $\mathbf{x}$ \\
\hline 2- Falta de pessoal & & $\mathbf{x}$ & & $\begin{array}{l}\text { 2- Comprometimento dos } \\
\text { associados }\end{array}$ & & & $\mathbf{x}$ \\
\hline 3- Controle orçamentário & & $\mathbf{x}$ & & $\begin{array}{l}\text { 3- Trabalho e bens de produção } \\
\text { coletivos }\end{array}$ & & & $\mathbf{x}$ \\
\hline $\begin{array}{l}\text { 4- Falta de um planejamento } \\
\text { bem definido }\end{array}$ & & & $\mathbf{x}$ & 4- Tecnologia a disposição & & $\mathbf{x}$ & \\
\hline $\begin{array}{l}\text { 5- Estrutura física } \\
\text { cedida/alugada }\end{array}$ & & & $\mathbf{x}$ & 5-Sintonia de objetivos & & & $\mathbf{x}$ \\
\hline $\begin{array}{c}\text { 6-Pouca estrutura física e } \\
\text { pessoal qualificado }\end{array}$ & & $\mathbf{x}$ & & $\begin{array}{l}\text { 6- Trabalho com respeito ao } \\
\text { meio ambiente }\end{array}$ & & & $\mathbf{x}$ \\
\hline $\begin{array}{l}\text { 7-Motivação somente por } \\
\text { recompensas, por objetivos. }\end{array}$ & & & $\mathbf{x}$ & $\begin{array}{l}\text { 7- Metodologia de trabalho } \\
\text { (pedagógico) }\end{array}$ & & & $\mathbf{x}$ \\
\hline $\begin{array}{c}\text { 8-Comunicação e Organização } \\
\text { interna }\end{array}$ & $\mathbf{x}$ & & & $\begin{array}{c}\text { 8- Forma de gestão - } \\
\text { construção coletiva de decisões }\end{array}$ & & & $\mathbf{x}$ \\
\hline $\begin{array}{l}9 \text { - Capacitação dos } \\
\text { trabalhadores }\end{array}$ & & $\mathbf{x}$ & & 9 -Empreendimento coletivo & & $\mathbf{x}$ & \\
\hline $\begin{array}{l}\text { TOTAL PARCIAL - } \\
\text { PONTOS FRACOS }\end{array}$ & 1 & 20 & 36 & $\begin{array}{l}\text { TOTAL PARCIAL - } \\
\text { PONTOS FORTES }\end{array}$ & $\mathbf{0}$ & 10 & 63 \\
\hline TOTAL PONTOS FRACOS & & 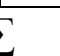 & 57 & TOTAL PONTOS FORTES & & $E$ & 73 \\
\hline
\end{tabular}

Conforme verificado, somou-se 73 pontos fortes e 57 pontos fracos, obtendo-se uma postura interna predominantemente forte.

$\mathrm{Na}$ análise interna verificou-se que a instituição depende de recursos externos especialmente para investimentos e manutenção de parte de suas atividades. Tais recursos são vitais para a COOPAVA, a qual necessita criar mecanismos para diminuir esta dependência, sob o risco de ter sua atividade comprometida caso cessem tais recursos.

Como ameaças destacam-se:

a) Órgãos controladores, legislação e possíveis mudanças da política econômica. É necessário adequar-se internamente para dar respostas a estas ameaças e também influenciar no ambiente externo e não somente ser influenciado por ele. 
b) As regras do mercado que resultam em variação de preços de matéria-prima e de produtos industrializados; órgãos controladores, em especial órgãos de liberação de licenças (ambiental e de operação); e as pressões colocadas pela legislação, uma vez que a cooperativa deve operar em total observância às leis (fiscais tributárias e registros institucionais como a junta comercial);

c) Mudanças políticas e econômicas, que por vezes interferem no planejamento da organização.

Entre as oportunidades, foram destacadas:

a) Engajamento da Cooperativa em projetos de parcerias, onde poderá comercializar parte dos produtos, abertura dos mercados cada vez maiores para produtos de base agroecológica e programas de governo.

b) Discussão sobre meio ambiente em alta, este fato poderá abrir oportunidades à organização, a qual trabalha também com meio ambiente;

c) Entidades parceiras;

d) Programas institucionais (aquisição de produtos);

e) Aumento da demanda por produtos com produção de base agroecológica.

O Quadro 4 apresenta sinteticamente o ambiente externo e apresenta as somas.

Quadro 4 - Análise das variáveis externas (oportunidades e ameaças) da COOPAVA.

\begin{tabular}{|c|c|c|c|c|c|c|c|}
\hline \multicolumn{8}{|c|}{ VARIÁVEIS EXTERNAS } \\
\hline OPORTUNIDADES & 1 & 5 & 9 & AMEAÇAS & 1 & 5 & 9 \\
\hline $\begin{array}{c}1 \text { - Possibilidade de algo diferente, } \\
\text { ideologia }\end{array}$ & & & $\mathbf{x}$ & $\begin{array}{l}1 \text { - Regras do mercado / } \\
\text { forma de constituição }\end{array}$ & & $\mathbf{x}$ & \\
\hline $\begin{array}{l}\text { 2- Discussões sobre meio ambiente } \\
\text { (agroecologia) em alta }\end{array}$ & & $\mathbf{x}$ & & $\begin{array}{l}2 \text { - Órgãos controladores e } \\
\text { dep. de recursos externos }\end{array}$ & & $\mathbf{x}$ & \\
\hline 3- Entidades Parceiras & & $\mathbf{x}$ & & $\begin{array}{c}\text { 3- Mudanças da política e } \\
\text { econômica }\end{array}$ & & & $\mathbf{x}$ \\
\hline $\begin{array}{l}\text { 4- Programas Institucionais } \\
\text { (colocação de produtos) }\end{array}$ & & $\mathbf{x}$ & & 4 - Legislação & & & $\mathbf{x}$ \\
\hline $\begin{array}{l}5 \text { - Várias entidades fazem parte da } \\
\text { cooperativa }\end{array}$ & & & $\mathbf{x}$ & $\begin{array}{l}\text { 5- Dependência de recursos } \\
\text { externos }\end{array}$ & & & $\mathbf{x}$ \\
\hline $\begin{array}{l}\text { TOTAL PARCIAL - } \\
\text { OPORTUNIDADES }\end{array}$ & $\mathbf{0}$ & 15 & 18 & $\begin{array}{c}\text { TOTAL PARCIAL - } \\
\text { AMEAÇAS }\end{array}$ & $\mathbf{0}$ & 10 & 27 \\
\hline TOTAL - OPORTUNIDADES & 2 & & 33 & TOTAL - AMEAÇAS & $\sum$ & & 37 \\
\hline
\end{tabular}

Conforme apresenta o Quadro 4 as oportunidades somam 33 pontos e as ameaças 37. Embora haja predominância de ameaças, foram elencadas oportunidades. Deverá a organização aproveitar as oportunidades transformando-as em ações concretas, o que irá trazer benefícios com vistas a atingir seus objetivos institucionais.

Helms (2010) e Henriques (2004) destacam que a partir dessa análise FOFA, a organização deverá usar seus pontos fortes para diminuir ou neutralizar o impacto das ameaças. Destacam ainda, que para potencializar as oportunidades, a organização poderá utilizar-se de alternativas de operacionalização simultânea da visão de longo prazo inerente ao planejamento estratégico.

$\mathrm{Na}$ organização estudada a ideologia é uma característica marcante, isso motiva o grupo e coloca a instituição numa condição de criar oportunidades. Uma vez estando com suas competências básicas entendidas e sendo conhecedora de suas fraquezas, poderá adequar-se para ser menos influenciada pelas ameaças. Ou seja, adequar-se às regras do mercado, órgãos controladores, fortalecer-se para as mudanças de ordem política e econômica, cumprir a legislação $\mathrm{e}$, dessa forma, potencializar as oportunidades. 


\subsection{Análise da postura estratégica}

Após análise dos dados, observa-se que a organização está numa postura estratégica de manutenção, já que há a predominância de ameaças do ambiente externo. Mas, internamente, possui uma série de pontos fortes acumulados ao longo do tempo (a ideologia, trabalho e bens de produção coletivos, sintonia de objetivos, recursos humanos, respeito ao meio ambiente, forma de gestão, etc.), que possibilitam sobreviver e manter a posição conquistada.

A Figura 1 destaca a posição da organização estudada de acordo com as postulações de Oliveira (1999).

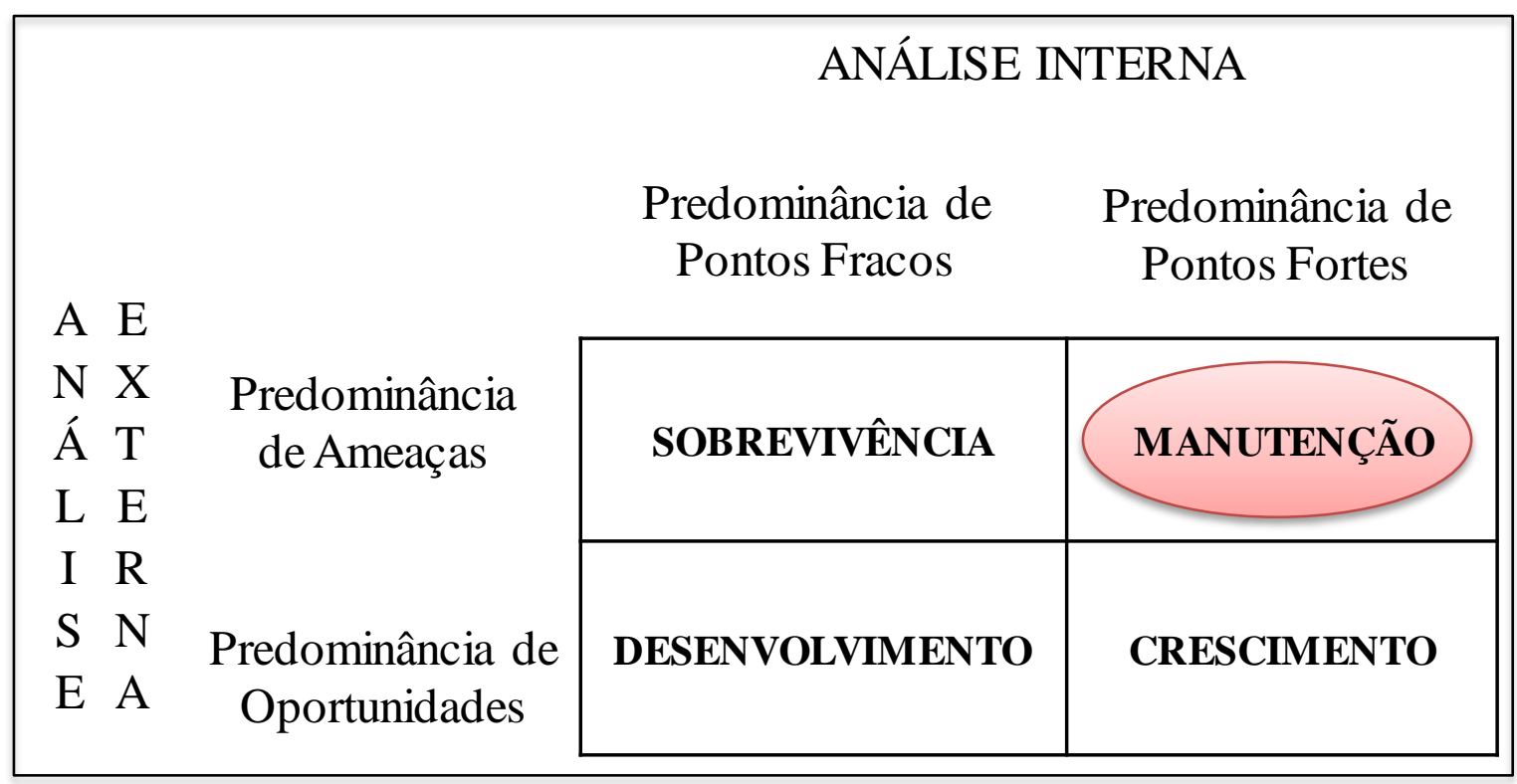

Figura 1 - Postura Estratégica. Fonte: Adaptado de Oliveira, 1999.

Observa-se que a posição da organização estudada é a de manutenção. A estratégia de manutenção é uma postura preferível quando a empresa está enfrentando ou espera encontrar dificuldades e prefere tomar uma atitude defensiva diante das ameaças. A organização em questão poderá, portanto, optar por manter um estado de equilíbrio e estratégia de nicho, concentrando os esforços para manter as vantagens competitivas que a cooperativa já tem.

Considerando a competência básica da Cooperativa estudada, a mesma alicerçou sua vantagem competitiva na produção de base agroecológica. Com isso, consegue colocar produtos diferenciados no mercado, atendendo uma demanda crescente, uma vez que o tema da alimentação saudável está em pauta na sociedade. Ou seja, nota-se que a estratégia competitiva adotada é a diferenciação.

Segundo Porter (1986) estratégia de diferenciação procura diferenciar a oferta da empresa dos concorrentes através da criação de um diferencial competitivo, que pode ocorrer sob as formas de marcas e atendimento personalizado, dentre outras dimensões. Esta estratégia não considera grandes volumes e preço baixo. Ao contrário, busca atender um número menor de clientes de uma forma mais personalizada, o que inviabiliza a conquista de grande participação de mercado.

Percebe-se na cooperativa um atendimento personalizado aos clientes, estando em contato frequente com os mesmos. Isto proporciona perceber as necessidades dos mesmos, o sentimento dos clientes em questões inerentes aos produtos, às suas necessidades e expectativas. Possui uma carteira de clientes que garante a colocação dos produtos no mercado, desta forma, cria barreiras de entrada aos concorrentes em virtude da lealdade obtida.

Além disso, o poder de barganha dos compradores é baixo por serem menos sensíveis ao preço e pelo baixo número de vendedores que atendam às suas necessidades de forma satisfatória. Assim, quando a organização busca ser a única em seu ramo, mediante procedimentos amplamente valorizados pelos clientes, está adotando uma estratégia de 
diferenciação. A diferenciação proporciona ainda, isolamento contra a rivalidade competitiva devido à lealdade dos consumidores com relação à marca e à menor sensibilidade ao preço (PORTER, 1986).

$\mathrm{Na}$ estratégia por diferenciação, os recursos e competências da organização devem ser direcionados para almejar novos mercados e maximização de lucros (PORTER, 1986). Isso pode ser observado na organização analisada, já que possui experiência no mercado regional e vem ampliando a carteira de clientes. Contudo, espera que com a ampliação da indústria, com o aumento da produção e inserção de novos produtos na linha de produção, possa prospectar novos mercados em centros maiores, mantendo a qualidade dos produtos, periodicidade na entrega, sem perder atendimento personalizado.

\section{Conclusão}

Resgatando o objetivo geral desta pesquisa, destaca-se que a mesma buscou analisar as estratégias de gestão de uma cooperativa dedicada à produção e processamento de produtos lácteos. A partir dessa investigação, constatou-se um esforço da organização analisada no sentido de propiciar uma gestão participativa, o que é coerente com a perspectiva cooperativista. Assim, a estratégica competitiva de diferenciação adotada pela organização é adequada aos seus propósitos, ao cenário de mercado que está inserida, bem como às suas forças e fraquezas.

Com este estudo, observa-se que é complexa a gestão de uma organização que tem por princípio a cooperação, mas atua num ambiente altamente competitivo. Mesmo com dificuldades, constata-se que é possível manter os princípios do cooperativismo, através da solidariedade, da participação e do trabalho coletivo.

Por outro lado, a postura estratégica observada de manutenção pressupõe cuidados e atenção para que possa continuar desenvolvendo sua missão. Dessa forma, a organização carece de planejamento estratégico, com plano de ação definido. Destacandose a necessidade de incluir nas discussões e planos da organização, a questão da participação e inclusão de jovens na cooperativa, assim como, formas de apoio governamental para isto.

Por fim, destacam-se ações pontuais de curto e médio prazo para melhoria da organização: correção do solo; calagem com adubação orgânica; patrulhas agrícolas com máquinas e equipamentos para infraestrutura de sustentabilidade da produção; aquisição coletiva de sementes, de adubos e de insumos para pastagem de verão e de inverno; aquisição coletiva de equipamentos de ordenha e resfriadores; estruturação de um centro de recria bovina para melhoramento genético do gado leiteiro; transporte do leite com frota própria; políticas de para associados junto à entidade.

\section{Referências Bibliográficas}

AZEVEDO, M. C. de; COSTA, H. Métodos para Avaliação de Postura Estratégica. Caderno de Pesquisas em Administração, v.8, n.2, 18p. São Paulo, 2001.

DIEHL, A. A.; TATIM, D. C. Pesquisa em ciências sociais aplicadas: métodos e técnicas. São Paulo: Prentice Hall, 2004.

FERREIRA, G. M. V. Governança e sua relação com fidelidade em cooperativas. Tese de Doutorado Curso de Doutorado do Programa de Pós Graduação em Extensão Rural, Universidade Federal de Santa Maria, RS, Brasil. 2014

HAGUETTE, T. M. F. Métodos qualitativos na sociologia. Petrópolis: Vozes, 2005.

HELMS, M.M.; NIXON, J. Exploring SWOT analysis - where are we now? A review of academic research from the last decade. Journal of Strategy and Management. vol. 3 n.. 3, pp.215$251,2010$.

HENRIQUES, J. P.. Análise, formulação $e$ implementação. 2004. Disponível em: http://student.dei.uc.pt/ jpdias/gestao/Strategic/\#A n?se_Formula?_e_Implementa? [Acesso em: 04 abr. 2015] MACHADO, M. Y. O. T. Gestão multicritério da competitividade: o caso da Cooperativa Agrícola Vista Alegre no assentamento Conquista da Liberdade em Piratini/RS. Tese de Doutorado. Programa de PósGraduação em Sistemas de Produção Agrícola Familiar da Universidade Federal de Pelotas, Pelotas, 2013. Disponível em: http://guaiaca.ufpel.edu.br/bitstream/123456789/2 385/1/Tese_morgan_yuri_oliveira_teles_machado. pdf. Acesso 01 de Outubro de 2016. 
MINAYO, M. C. S. et al. Pesquisa social: teoria, método e criatividade. Petrópolis: Vozes, 1994.

MONTAÑO, C. Terceiro Setor e a questão social: crítica ao padrão emergente de intervenção social. São Paulo: Editora Cortez, 2012.

OLIVEIRA, D. P. R. Planejamento Estratégico: Conceitos, metodologia e práticas: São Paulo: Atlas, 1999.

PORTER, M. E. Competitive Advantage: Creating and Sustaining Competitive Performance. New York: The Free Press, 1986.

REIS, L. G. da C. Administração - noções gerais. $2013 . \quad$ Disponível em: http://www.rits.org.br/gestao_teste/ge_testes/ge_m at01_adm_admtxt1.cfm/. [Acesso em: 19 fev. 2015].

SEBRAE. Serviço Brasileiro de Apoio às Micro e Pequenas Empresas. 2015. Disponível em: http://www.sebrae.com.br/. [Acesso em: 20 de abr. 2015].

SIMCH, T. L. Produção familiar na agricultura: um exemplo de tipologia no município de Canguçu/RS. Local. [Tese de Doutorado] Pelotas: EDUFPEL, 2002.

SOUZA, E. C. L.; Atitude empreendedora em proprietários-gerentes de pequenas empresas: construção de um instrumento de medida - IMAE. READ, 48 ed., v. 11, nov./dez. 2005.

TURATO, E.R. Tratado da Metodologia da Pesquisa Clínico-Qualitativa. Petrópolis, Ed. Vozes,2003.

YIN, Robert K. Estudo de caso: planejamento e métodos/ Trad. Daniel Grassi - $2^{\circ}$ Ed. - Porto Alegre: Bookman, 2001.

VALADARES, J. H. A moderna administração em cooperativas. Rio de Janeiro.- MBA em Gestão Empresarial em Cooperativas de Saúde Realização Fundação Getulio Vargas - Cursos "in Company”. 2014. 
